\title{
GEOTECNOLOGIAS E MÉTRICAS APLICADAS NA ANÁLISE DA PAISAGEM DA BACIA DO RIO AGUAPEÍ/MT, BRASIL
}

\author{
GEOTECHNOLOGIES AND METRIC APPLIED TO THE ANALYSIS OF THE \\ LANDSCAPE IN RIVER BASIN OF RIVER AGUAPEÍ/MT, BRAZIL
}

\author{
Laís Fernandes de Souza Neves \\ lais_geografia@hotmail.com \\ Universidade do Estado de Mato Grosso
}

Sandra Mara Alves da Silva Neves ssneves@unemat.br Universidade do Estado de Mato Grosso

\author{
Ronaldo José Neves \\ rjneves_geo@hotmail.com \\ Universidade do Estado de Mato Grosso
}

\begin{abstract}
RESUMO
Objetivou-se analisar as mudanças estruturais da paisagem da Bacia Hidrográfica do Rio Aguapeí/MT, nos anos de 1991 e 2011, através do uso das geotecnologias e métricas. Este estudo é baseado numa abordagem categórica, cujas classes discretas pertencentes à cobertura vegetal e uso da terra foram identificadas e mapeadas por meio das Geotecnologias e caracterizadas quantitativamente por índices de Ecologia de Paisagem, adotando o modelo conceitual de "mancha-corredor-matriz". Verificou-se que a paisagem da área de estudo forma um mosaico, apresentando uma matriz constituída por Savana (Cerrado), com diversas manchas de Agropecuária e uma de área de Influência urbana, sendo que esta última classe não existia em 1991, e o corredor formado pela Floresta aluvial do Rio Aguapeí. Os dados evidenciaram um decréscimo da área ocupada pela vegetação de Savana e o crescimento da atividade agropecuária no período analisado. Caso este padrão seja mantido, indica que nos próximos 20 anos poderá a matriz da bacia ser constituída pela atividade agropecuária implicando em simplificação dos ecossistemas. Sendo assim, há necessidade de que as políticas de desenvolvimento regional de Mato Grosso priorizem a conservação ambiental, o que irá refletir no planejamento do uso da terra, para melhorar a permeabilidade da paisagem.

Palavras-chave: Fragstats, Uso da terra, Sensoriamento Remoto.
\end{abstract}

\footnotetext{
ABSTRACT

The objective of this study was to analyze the structural changes of the landscape in the River Basin of the Aguapeí River/MT, in the years 1991 and 2011, through the use of geotechnologies and metrics. This study is based on a categorical approach, which classes discrete belonging to the vegetation cover and land use were identified and

Geo UERJ. Rio de Janeiro - Ano 16, no . 25, v.2, $2^{\text {o }}$ semestre de 2014, pp.397-418

ISSN: 1415-7543 E-ISSN: 1981-9021

http://www.e-publicacoes.uerj.br/index.php/geouerj
} 
mapped by means of geotechnologies and characterized quantitatively by indices of Landscape Ecology, adopting the conceptual model of "stain-corridor-matrix'. It was found that the landscape of the study area form a mosaic, showing an array consisting of savanna (Cerrado), with several spots of livestock, and an area of influence urban, being that the latter class did not exist in 1991, and the corridor formed by alluvial forest in River Basin of the Aguapeí. The data showed a decrease in the area occupied by savanna vegetation and the growth of the agricultural activity in the period analyzed. In case of this pattern is maintained, indicates that in the next 20 years may be the matrix of the basin be constituted by agricultural activity resulting in simplification of ecosystems. Thus, there is a need for regional development policies of Mato Grosso prioritize environmental conservation, which will reflect in land use planning, to improve the permeability of the landscape.

Keywords: Fragstats, land use, remote sensing.

\section{INTRODUÇÃO}

O termo paisagem é polissêmico e a sua conceituação está associada à perspectiva de um observador, assim na visão antropocêntrica pode ser definida como um conjunto de unidades de uso e cobertura do território, prevalecendo critérios fisionômicos, composicionais ou de utilidade para sociedade (METZGER et al., 2007).

A paisagem da região sudoeste mato-grossense, onde se encontra inserida a área de estudo - a Bacia Hidrográfica do Rio Aguapeí - BHRA era extensivamente recoberta pela vegetação de Savana e de Florestas até o final da década de 1960, quando foram criadas as políticas públicas que objetivavam estimular a ocupação regional, a expansão da fronteira agrícola e a modernização da agricultura, resultando em amplas transformações territoriais. Silva e Sato (2012) expõe que a partir da década de 1970 a colonização reforçou outro sentido de que as terras que se situavam em Mato Grosso eram consideradas "espaços vazios", sendo necessário abrir a fronteira, embora esses espaços jamais foram vazios. Eram assim denominados por não serem consideradas as populações locais e tão pouco seus ecossistemas. O discurso nacionalista "integrar para não entregar" e a promessa "terras sem homens para homens sem terra" predominaram naquele período e foi decisivo na ocupação regional.

A década de 1980 foi caracterizada pela realização de projetos de colonização, baseados em assentamentos de famílias em pequenas propriedades, entretanto estes acabaram limitados e tiveram suas chances de sucesso reduzidas por diversos 
elementos, tais como: características qualitativas da terra; dificuldade de acesso ao crédito por parte dos pequenos agricultores, etc.

Na década seguinte, principalmente a partir de 1995, a política de reforma agrária criou 62 assentamentos rurais na região sudoeste de Mato Grosso. O exposto ocorreu em uma região cuja base econômica esta sustentada na atividade pecuária, que vem penetrando cada vez mais nas áreas florestais. Este aspecto é ressaltado por Egler (2000), que mostra como o capital financeiro tem investido na constituição de uma forte economia agropastoril no estado de Mato Grosso. O que é extremamente prejudicial para o produtor familiar e causaram ainda fortes impactos socioambientais, pois essa atividade demanda a supressão da vegetação, depois a realização das queimadas e por fim a inserção de espécies exóticas de capim. Assim, a pecuária acaba sendo a alternativa mais imediata para a valorização da terra.

Isto posto, este estudo parte do princípio que as políticas públicas pretéritas de ocupação e as vigentes de estruturação produtiva de Mato Grosso promovem ou contribuem de forma precoce para a transformações na estrutura da paisagem, no caso em tela da região sudoeste mato-grossense, o que acarreta importantes implicações a conservação ambiental. Tal possibilidade é norteada na afirmação de Cunha (2006) que ao investigar a região Centro-Oeste e, particularmente, o Mato Grosso afirmou que o Estado possui uma economia com caráter essencialmente agrícola e urbanização crescente, mas ainda com extensas áreas de matas e florestas. Estas características formam o retrato da sua diversidade demográfica e ambiental, que são capazes de explicar seu grande dinamismo econômico nos últimos anos.

Portanto, como um dos resultados das atividades antrópicas desenvolvidas na região tem-se a intensa redução e fragmentação da vegetação e, em alguns casos sua total supressão, constituindo um fato preocupante, pois a cobertura vegetal natural é um importante indicador das condições ambientais (SILVA et al., 2011). O processo de fragmentação leva à formação de uma paisagem em mosaico cuja estrutura é constituída por três componentes horizontais básicos: manchas ou fragmentos, corredores e a matriz (METZGER, 2003).

A matriz é o elemento que tem domínio ou que controla a dinâmica da paisagem, em geral, reconhecida pelo predomínio de área ocupada no espaço, com menor grau de fragmentação; as manchas são os fragmentos não lineares de aparente homogeneidade, 
que interrompem a matriz; enquanto os corredores são os elementos lineares de aparente homogeneidade e distinguíveis na matriz (FORMAN e GODRON, 1986; SANTOS, 2004). Assim, o conhecimento destes elementos de uma paisagem é essencial para a caracterização de sua estrutura e para a identificação de seus padrões.

Santos (2007) mostra que a estrutura é a representação morfológica dos elementos da paisagem. Está corrobora com a sua distribuição espacial e pode ser representada por manchas, contínuas ou descontínuas, lineares ou fragmentadas, podendo ser relacionada à sua função ecológica. Dunning et al. (1992) e Turner (1989), discorrem que a estrutura de uma paisagem deve ser caracterizada e ter seus padrões definidos com base na sua configuração e composição. No contexto deste estudo será investigada a configuração da paisagem, por referir-se à distribuição física ou caracterização espacial dos elementos na paisagem (MCGARIGAL e MARKS, 1995), numa perspectiva espaço-temporal.

Leitão (2002); Herold et al. (2003); Dietzel et al. (2005); Weins (2005); Bertolo (2009), entre outros pesquisadores utilizaram métricas da paisagem para mensurar as características espaciais ao longo do tempo visando identificar um padrão espaçotemporal para suas áreas de estudo. Desta forma, o mapa de uso da terra e cobertura vegetal, elaborado em Sistemas de Informação Geográfica - SIG utilizando imagens de sensoriamento remoto, possibilita a caracterização quantitativa da estrutura da paisagem e a identificação de padrões (VALENTE, 2001). A quantificação da estrutura é um elemento chave para a elaboração de estratégias de manejo de paisagens (BASKENT, 1997), que devem ser contempladas num processo de planejamento ambiental.

Diante do exposto, este estudo objetivou analisar as mudanças estruturais da paisagem da Bacia Hidrográfica do Rio Aguapeí/MT, nos anos de 1991 e 2011, através do uso das geotecnologias e métricas.

Portanto, espera-se no âmbito deste estudo gerar repostas para as seguintes indagações: como está estruturada na atualidade a paisagem da bacia de estudo? Como a organização espacial, definida pelos atores sociais, interferiu na conservação da paisagem da BHRA? É possível identificar um padrão considerando a perspectiva espaço-temporal?

A análise da estrutura da paisagem apresentado neste estudo foi baseado numa abordagem categórica, cujas classes discretas pertencentes à cobertura vegetal e uso da terra foram identificadas e mapeadas por meio das geotecnologias e caracterizadas 
quantitativamente por índices de Ecologia de Paisagem, adotando o modelo conceitual de "mancha-corredor-matriz", que segundo Metzger (2007) é o mais empregado para se definir os elementos da paisagem em função de sua disposição espacial.

\section{MATERIAL E MÉTODOS}

\section{Área de estudo}

A Bacia Hidrográfica do Rio Aguapeí totaliza uma área de 188.740 ha, estando situada no município de Porto Esperidião, pertencente à região sudoeste de planejamento do estado de Mato Grosso (Figura 1). O rio Aguapeí é o principal afluente do rio Jauru, percorrendo toda a extensão territorial municipal, no sentido oeste-leste. O rio Jauru por sua vez é um dos principais afluentes do Rio Paraguai, que drena todo o bioma Pantanal.

\section{Procedimentos metodológicos}

Para a elaboração dos mapas da cobertura vegetal e uso da terra foram utilizadas as imagens Landsat, sensor Thematic Mapper, correspondente a órbita/ponto 228/71, bandas 3, 4 e 5, com resolução de 30m, dos anos de 1991 e 2011, disponibilizadas no sítio do Instituto Nacional de Pesquisas Espaciais - INPE.

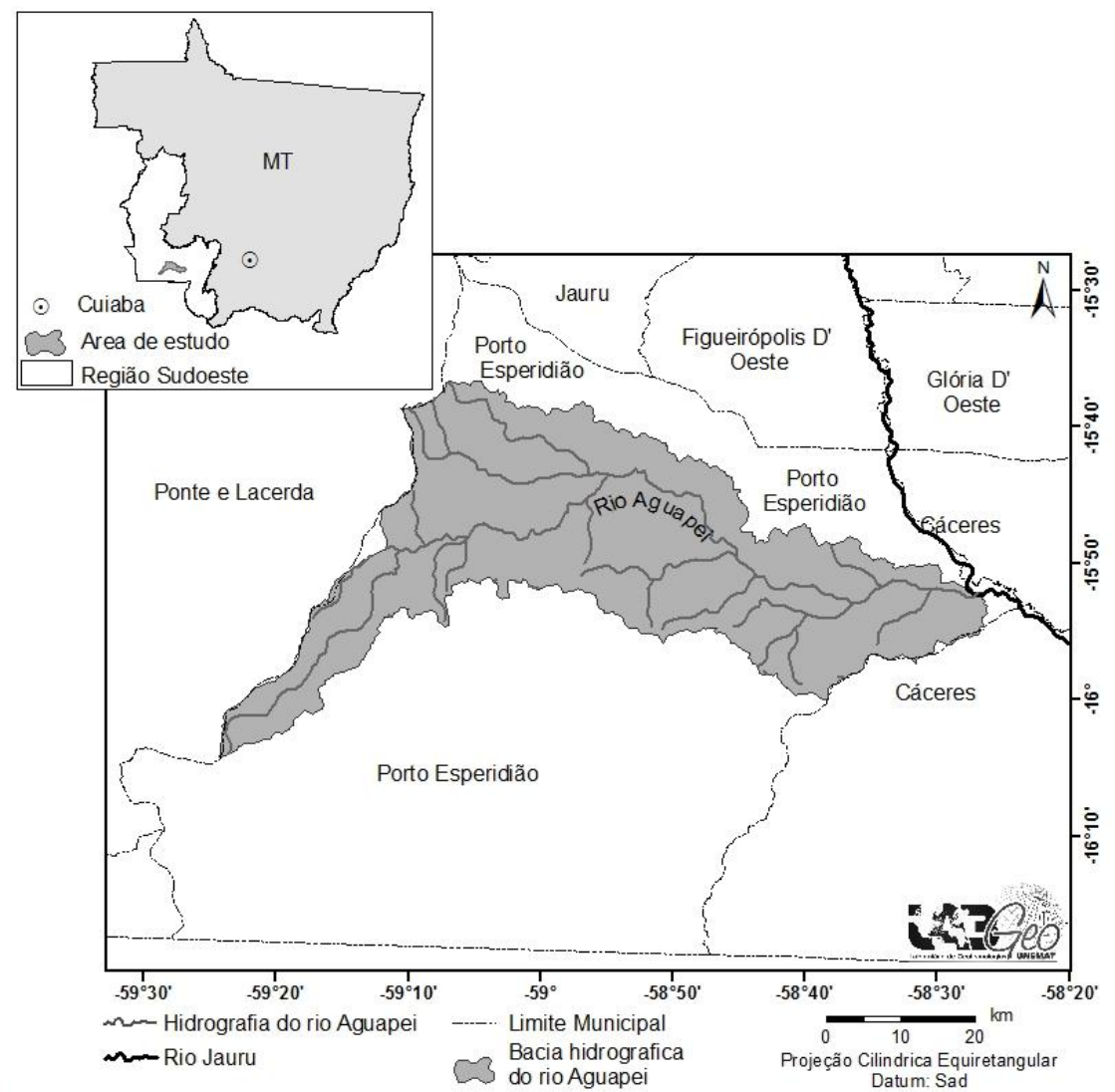

Geo UERJ. Rio de Janeiro - Ano 16, no . 25, v.2, $2^{\circ}$ semestre de 2014, pp.397-418 ISSN: 1415-7543 E-ISSN: 1981-9021

http://www.e-publicacoes.uerj.br/index.php/geouerj 
Figura 1. Localização da Bacia Hidrográfica do rio Aguapeí - BHRA/MT.

As imagens foram georreferenciadas no Sistema de Processamento de Informações Georreferenciadas - SPRING, versão 4.3.3, do INPE (CÂMARA et al., 1996) utilizando como referência a imagem Landsat/Geocover, apresentando erro de 0,5 pixel. Na sequência foi aplicado realce linear para melhor discriminação dos alvos, feita segmentação (área 10 e similaridade 10) e classificação. Para proceder à classificação dos alvos foram utilizados os elementos de interpretação descritos por Florenzano (2002) e para as nomenclaturas das classes adotou-se a proposta utilizada no Projeto de Conservação e Utilização Sustentável da Diversidade Biológica - PROBIO (BRASIL, 2007). A escala dos produtos cartográficos utilizados nesta pesquisa foi de 1 : 250.000 e os mapas apresentados no corpo deste artigo estão na escala de 1:700.000, o que impossibilita a visualização de algumas classes mapeadas nas representações.

O mapa clinográfico da área de estudo foi gerado através da utilização dos modelos digitais de elevação obtidos a partir do radar interferométrico da Shuttle Radar Topography Mission - SRTM, com resolução espacial de $30 \mathrm{~m}$, por meio da ferramenta Surface/Slope, disponível na extensão 3D Analyst no ArcGis, versão 9.2 (ESRI, 2007). Procedeu-se na sequência o fatiamento através da opção de propriedades da layer Symbology/reclassify, estabelecendo-se cinco classes de declividade com correspondência qualitativa, conforme proposto por Brasil (2007). Para finalizar a elaboração do mapa houve a conversão para o formato vetorial através da extensão Spatial Analyst.

De acordo com Ritters et al. (1995), o ideal na quantificação da estrutura das paisagens é que se tenha uma pequena variedade de índices, os quais permitam obter em curto espaço de tempo, o mais importante da estrutura e do padrão de uma paisagem. Os autores concluíram o exposto após avaliarem 56 índices e constatarem que 6 índices univariados foram suficientes para conhecer a estrutura e o padrão de uma paisagem fragmentada (VALENTE, 2001).

Neste sentido, para seleção das métricas foram considerados o objetivo deste estudo, as perguntas norteadoras e as métricas indicadas nos trabalhos de Turner et al. (1996) e Koivu (1999) como relevantes e pertinentes para análise proposta neste estudo, considerando que as métricas utilizadas têm como objetivo mostrar como é a estrutura e a relação espacial entre diferentes elementos presentes na paisagem investigada.

Geo UERJ. Rio de Janeiro - Ano 16, nº. 25, v.2, $2^{\circ}$ semestre de 2014, pp.397-418 ISSN: 1415-7543 E-ISSN: 1981-9021

http://www.e-publicacoes.uerj.br/index.php/geouerj 
O cálculo dos índices relativos aos fragmentos individuais, aos tipos de classe e a paisagem como um todo, apresentados a seguir, foi realizada no software Fragstats, versão 3.3 (MCGARIGAL e MARKS, 1995) utilizando o arquivo da classificação da cobertura vegetal e uso da terra na extensão grid. Pois, segundo Volotão (1998), o Fragstats (MACGARIGAL \& MARKS, 1995) pode ser definido como um conjunto de ferramentas auxiliares da análise espacial da paisagem, através de índices que se dividem em três níveis: fragmentos, classes e paisagem.

As métricas quantificadas foram:

- Área (CA) calcula a área (ha) da classe por meio da equação:

$$
\begin{gathered}
C A=\sum_{j=1}^{n} a_{i j} \frac{1}{10.000} \\
a_{i j} \text { área }\left(\mathrm{m}^{2}\right) \text { da mancha } i j
\end{gathered}
$$

- Porcentagem da paisagem (PLAND) é a divisão da área da classe pela área total da paisagem calculada através da equação:

$$
P L A N D=p_{i}=\frac{\sum_{j=1}^{n} a_{i j}}{A}(100)
$$

$p_{i}$ - proporção da paisagem ocupada pela mancha tipo (classes) $\mathrm{i}$

$$
a_{i j} \text {-área }\left(\mathrm{m}^{2}\right) \text { da mancha } \mathrm{ij}
$$

$$
\text { A - área total da paisagem }\left(\mathrm{m}^{2}\right)
$$

- Total de bordas (TE) soma de todas as bordas da classe calculada pela equação:

$$
T E=\sum_{k=1}^{m} e_{i k} e_{i k} \text { tamanho total da orla entre tipos (classe) de manchas } i \text { e } k
$$

- Área central total (TCA) soma das áreas centrais da classe obtidas por meio da equação:

$$
\begin{gathered}
T C A=\sum_{j=1}^{n} a_{i j}^{c} \frac{1}{10.000} \\
a_{i j}^{c} \text { área }\left(\mathrm{m}^{2}\right) \text { da mancha } i j \text { com um valor de buffer especificado }(\mathrm{m})
\end{gathered}
$$

- Percentual da área central (CPLAND) soma da area central total da classe dividido pela area total da paisagem calculada pela equação: 


$$
C P L A N D=\frac{\sum_{j=1}^{n} a_{i j}^{c}}{A}(100)
$$

$a_{i j}^{c}$ - área $\left(\mathrm{m}^{2}\right)$ do núcleo da mancha ij com um valor de buffer especificado (m)

$$
\text { A - área total da paisagem }\left(\mathrm{m}^{2}\right)
$$

- Distância euclidiana de menor vizinhança (ENN) é a soma de todas as distâncias entre cada fragmento e o vizinho mais próximo da mesma classe, dividido pelo número de fragmentos da classe através da equação:

$$
E N N=h_{i j}
$$

$h_{i j}$ distância da mancha $i j$ à mancha de vizinhança mais próxima com o mesmo tipo de classe, baseada na distância borda a borda

- Número de mancha (NP) calcula o número total de mancha na paisagem através da equação:

$$
N P=n_{i}
$$

$n i$ número de manchas do tipo (classe) $i$ na paisagem

- Conectividade entre os fragmentos (COHESION) soma da conectividade fisica entre cada fragmento da mesma classe aatravés da equação:

$$
\text { COHESION }=\left[1-\frac{\sum_{j=1}^{n} p_{i j}}{\sum_{j=1}^{n} p_{i j} \sqrt{a_{i j}}}\right]\left[1-\frac{1}{\sqrt{A}}\right]^{-1} \text { (100) }
$$

$A$ é a área total da paisagem $\left(\mathrm{m}^{2}\right)$. $p_{i j}$ é o perímetro $(\mathrm{m})$ damancha $\mathrm{ij} \mathrm{a}_{\mathrm{ij}}-$ área $\left(\mathrm{m}^{2}\right)$ da mancha ij

- Índice de maior mancha (LPI) calcula a porcentagem da paisagem ocupada pelo maior mancha na classe, sendo esta gerada via a equação:

$$
L P I=\frac{\max _{j=1}^{n}\left(a_{i j}\right)}{A}(100)
$$

$a_{i j}$ área $\left(\mathrm{m}^{2}\right)$ da mancha $i$

$A$ área $\left(\mathrm{m}^{2}\right)$ total da paisagem 
A matriz foi definida pelo método da área relativa proposto por Forman e Godron (1986), como sendo a classe de cobertura do solo de maior área na paisagem. Após a definição da matriz, os demais polígonos não lineares e com certa heterogeneidade foram definidos como manchas e os lineares e com certa homogeneidade como corredor.

A partir da integração dos dados primários e secundários foram realizadas as análises, confrontando os resultados obtidos com os apresentados em bibliografias, estabelecendo assim as discussões.

\section{RESULTADOS E DISCUSSÃO}

A bacia hidrográfica do Rio Aguapeí no ano de 1991 apresentava 75,58\% de sua área recoberta por Savana (Cerrado), 2,23\% de Floresta Aluvial, 22\% de Agropecuária e 0,19\% de água. No ano de 2011 a paisagem da BHRA encontrava-se estruturada pelas classes de Savana (Cerrado) que recobre 52\% de sua dimensão territorial, Floresta Aluvial com 8\%, Agropecuária com 39\% e as áreas ocupadas pelas classes de Água e Influência urbana, que corresponderam a 1\%, respectivamente (Tabela 1 e Figura 2).

Tabela 1: Dados relativos à cobertura vegetal e o uso da terra da área de estudo.

\begin{tabular}{l|r|r|r}
\hline \multirow{2}{*}{$\begin{array}{l}\text { Classes de cobertura } \\
\text { vegetal e uso da terra }\end{array}$} & \multicolumn{2}{|c|}{ Área (ha) } & \multicolumn{1}{c}{\begin{tabular}{c} 
Mudanças \\
\cline { 2 - 3 }$(\%)$
\end{tabular}} \\
\hline Savana (Cerrado) & 143.818 & $\mathbf{2 0 1 1}$ & \\
Floresta aluvial & 4.18 & 15.304 & $-31,02$ \\
Agropecuária & 40.359 & 73.904 & 864,09 \\
Água & 366 & 274 & $-25,13$ \\
Influência urbana & 0 & 53 & \\
\hline Total & $\mathbf{1 8 8 . 7 4 0}$ & $\mathbf{1 8 8 . 7 4 0}$ & - \\
\hline
\end{tabular}




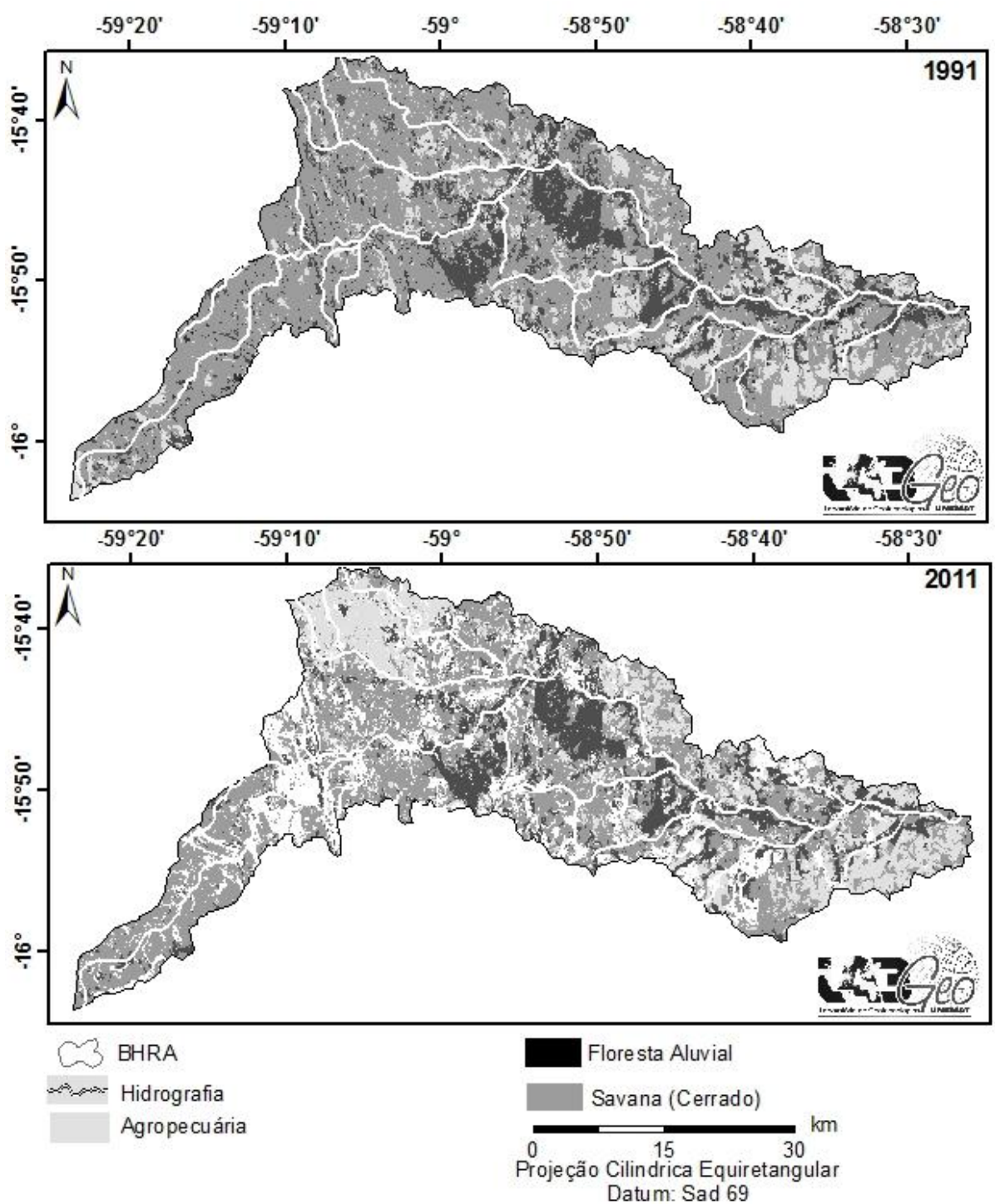

Figura 2. Cobertura vegetal e uso da terra da Bacia Hidrográfica do Rio Aguapeí nos anos de 1991 e 2011.

Os dados relativos aos percentuais de mudanças ocorridas na cobertura vegetal e uso da terra na bacia investigada mostram como a organização espacial, definida pelos atores sociais, interferiu na conservação da paisagem da BHRA, evidenciando um decréscimo da área ocupada pela vegetação de Savana (Cerrado) e o crescimento da atividade agropecuária no período analisado.

Caso o padrão apresentado, no período de análise, seja mantido indica que no decorrer de 20 anos poderá ocorrer a alteração na matriz da bacia, passando esta a ser constituída pela atividade Agropecuária, considerando como parâmetro o crescimento apresentado pela atividade e a redução da Savana (Cerrado). O exposto é de conhecimento da gestão pública, pois no Plano de Logo Prazo de Mato Grosso Geo UERJ. Rio de Janeiro - Ano 16, nº. 25, v.2, $2^{\circ}$ semestre de 2014, pp.397-418 
MT+20 (MATO GROSSO, 2012), utilizado para direcionar a gestão do desenvolvimento do Estado no período de 2005 a 2025 descreveu que a forte expansão da agropecuária no território estadual provocou alterações no ambiente natural, com diferentes graus de intensidades e degradando os recursos naturais.

O Programa Integrado de Desenvolvimento do Noroeste do Brasil (Polonoroeste) realizado na década de 80 na área de influência da rodovia BR-364, entre Cuiabá (MT) e Porto Velho (RO), incentivou a ocupação regional e o aumento da produção da região. Como uma das consequências dessa política foi que áreas recobertas por vegetação deram, ao longo dos anos, lugar às culturas agrícola, principalmente as pastagens para a pecuária bovina, que manteve amplo predomínio até os dias atuais.

Sobre o assunto, Oliveira (2004) argumentou que esse avanço da agropecuária sobre o Cerrado é visto como fator de desenvolvimento da região Centro-Oeste e, mais recentemente, tem tido papel importante na retomada do crescimento econômico do Brasil, na medida em que o agronegócio amplia sua participação no mercado externo, via exportação de produtos como a carne bovina e a soja. Sendo que no caso da área de estudo predomina na classe agropecuária a atividade de pecuária, que constitui a principal atividade econômica da região sudoeste mato-grossense.

No Plano de desenvolvimento de Mato Grosso - MT+20 (MATO GROSSO, 2012) é abordado a necessidade de consolidação de áreas legalmente protegidas e o controle mais rigoroso do desmatamento, estes contribuíram para diminuir os efeitos das pressões antrópicas decorrentes, sobretudo, da expansão das atividades econômicas e do crescimento demográfico. O fortalecimento do sistema de gestão ambiental do Estado pode melhorar a relação entre a economia e o meio ambiente, pois favorecer o crescimento econômico com preservação dos recursos naturais constitui um diferencial importante para o desenvolvimento de Mato Grosso.

A partir dos dados apresentados na tabela 2 e a luz do modelo conceitual de "mancha-corredor-matriz" verificou-se que a paisagem da área de estudo forma um mosaico, apresentando uma matriz constituída por Savana (Cerrado), com diversas manchas de Agropecuária e uma de área de Influência urbana, sendo que esta última classe não existia em 1991, o corredor formado pela Floresta aluvial do Rio Aguapeí e as Águas do Rio Aguapeí (Figura 3).

Geo UERJ. Rio de Janeiro - Ano 16, nº 25, v.2, $2^{\text {o }}$ semestre de 2014, pp.397-418

ISSN: 1415-7543 E-ISSN: 1981-9021

http://www.e-publicacoes.uerj.br/index.php/geouerj 
Tabela 2. Cobertura da terra e estrutura da paisagem da área de estudo

\begin{tabular}{lrrrrrr}
\hline Cobertura vegetal & \multicolumn{2}{c}{ Área (\%) } & \multicolumn{3}{c}{ Estrutura da paisagem } \\
\cline { 5 - 6 } e uso da terra & $\mathbf{1 9 9 1}$ & $\mathbf{2 0 1 1}$ & Matriz & Mancha & Corredor \\
\hline Savana (Cerrado) & 75,58 & 52 & Cerrado & Agropecuária & Floresta Aluvial \\
Agropecuária & 22 & 39 & & Influência urbana & Água \\
Floresta aluvial & 2,23 & 8 & & & \\
Água & 0,19 & 0,58 & & & \\
Influência urbana & - & 0,42 & & & \\
\hline Total & 100 & 100 & & & \\
\hline
\end{tabular}
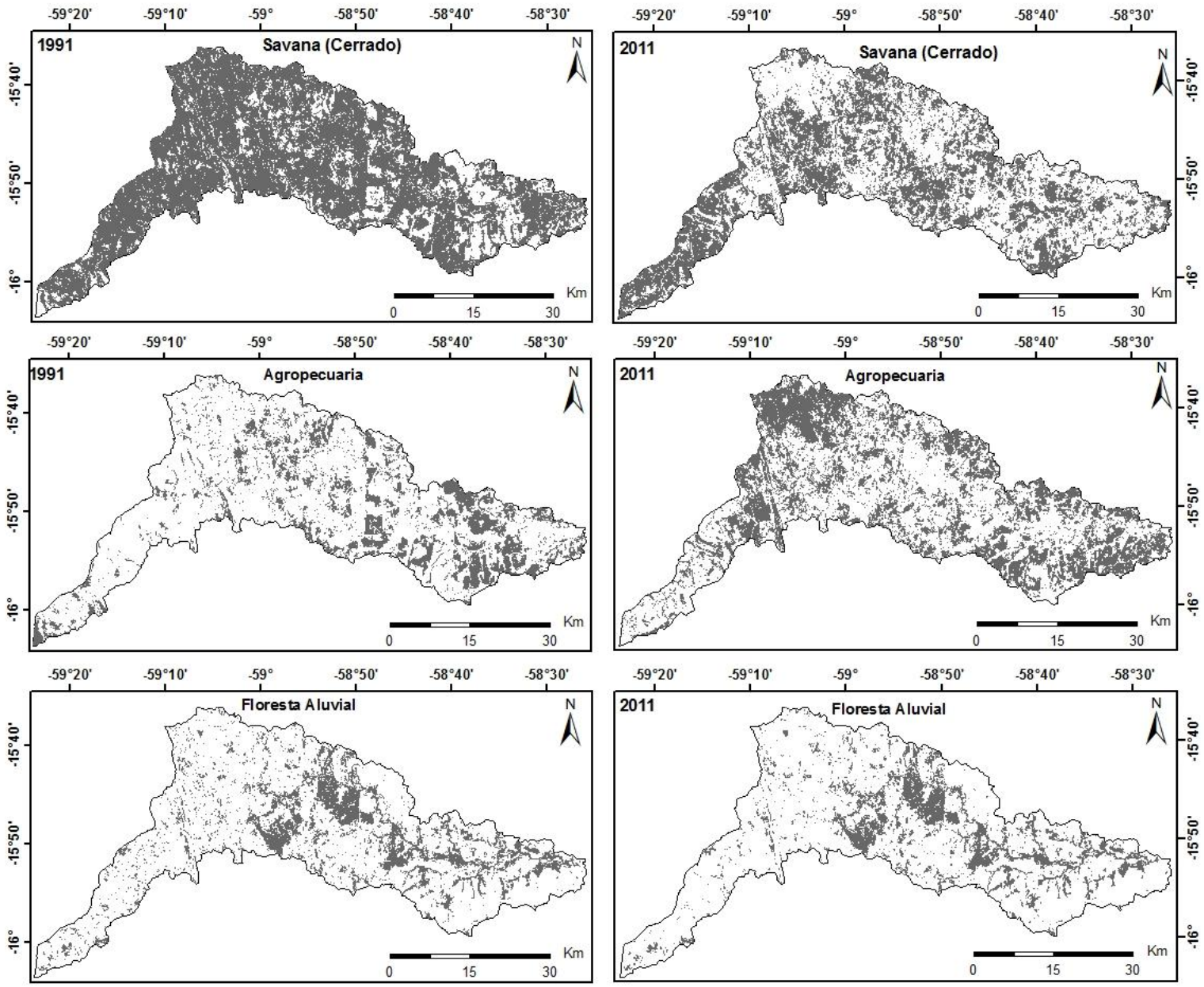

Figura 3. Distribuição dos elementos da paisagem da Bacia Hidrográfica do Rio Aguapeí nos anos de 1991 e 2011.

A predominância de vegetação Savana (Cerrado) a caracteriza como matriz, por ser o elemento mais extenso e por exercer um maior controle na dinâmica da paisagem (fluxos de matéria, energia e espécies), colaborando para a conservação ambiental. De 
acordo com Forman e Godron (1986) a matriz é o pano de fundo da paisagem controlando sua dinâmica e afetando os fragmentos e corredores.

Os dados relativos à matriz formada pela Savana (Cerrado) mostram que em ambos anos analisados esta não apresentou-se de forma contínua na área de estudo, mas perfurada pela presença de manchas, que referem-se aos usos. Segundo Metzger (2007), a matriz pode afetar a fragmentação, sendo que uma maior permeabilidade da matriz aos fluxos biológicos pode atenuar os efeitos da fragmentação, e servir como alternativa de manejo para aumento da conectividade da paisagem.

Ao analisar a origem das manchas da área de estudo, com base no exposto por Forman e Godron (1986) verificou-se que estas são do tipo machas introduzidas (Introduced patches) correspondendo à introdução humana de usos (atividades agrícolas).

De acordo com Marsh (1997) o corredor da área em investigação pode ser classificado quanto a sua estrutura em margens de linha de água (stream (riparian) corridors) podendo controlar o fluxo de água, nutrientes, minerais, reduzindo assim a probabilidade de cheias, assoreamento e perda de fertilidade do solo.

De acordo com os resultados das métricas TE, TCA e CPLAND, apresentados na tabela 3, averiguou-se que houve alteração no número total de bordas (TE) e no total de áreas centrais (TCA) das classes, no decorrer dos anos de estudo. Devido à redução de áreas de bordas na classe de Savana (Cerrado), ocorreu consequentemente uma redução no total de áreas centrais. Sobre o assunto, Valente (2001) manifesta que fragmentos de floresta nativa com área inferior a 1ha não apresentam área central, em função do seu tamanho estão submetidos a total influência da matriz (efeito de borda).

A classe Savana (Cerrado) apresentou uma redução de 636\% implicando em perda de biodiversidade vegetal com implicações na fauna, pois esta classe é reconhecida como a mais rica do mundo e abriga uma ampla diversidade de espécies da flora e da fauna (MATO GROSSO, 2012). Sevegnani et al. (2012) constataram a redução da diversidade de espécies nativas inclusive que algumas ameaçadas de extinção ocorrem devido ao impacto constante da agricultura e pecuária no entorno dos fragmentos de remanescentes florestais.

A classe Água decresceu $14 \%$ no total de áreas centrais, entretanto os valores obtidos para a classe não refletem a realidade devido à resolução espacial da imagem, 
que não permitiu a sua correta discriminação. As demais classes apresentaram aumento decorrente à relação entre total de bordas e total de áreas centrais, com isso a classe Agropecuária e Floresta aluvial obtiveram 119\% e 321\% de aumento, respectivamente. Segundo Valente (2001), em vegetações de Cerrado é complexo determinar a área nuclear (central) mínima necessária para que os fragmentos sejam considerados remanescentes da biodiversidade e tenham condições de manter sua estrutura interna. Porém sabe-se, que fragmentos maiores e não isolados em uma paisagem, têm melhores condições de se manterem e sustentarem a vida animal do que os memores e mais isolados.

Numa paisagem fragmentada, com quantidade elevada de fragmentos, a característica mais acentuada é o incremento de borda, que por sua vez modifica as condições microclimáticas (insolação, umidade relativa, velocidade dos ventos e entre outros), o que provavelmente, influência na alteração da estrutura da vegetação por implicar na mortalidade de árvores e na mudança da comunidade vegetal.

Vieira (2010) corrobora com o exposto ao afirmar que bordas criadas por ação humana estabelecem influências negativas adjacentes, que afetam a densidade e a composição das comunidades vegetais, provocando diversos tipos de desequilíbrios. Entretanto, o número elevado de fragmentos pode ser positivo, se for considerado que este facilita o deslocamento de pequenos mamíferos e de aves de pequeno porte. Fragmentos menores (sem área nuclear) não podem ser desconsiderados em uma paisagem, porque desempenham um papel importante na conservação de sua estrutura florestal, que é a conexão entre fragmentos de florestas (VALENTE, 2001).

Tabela 3. Total de bordas (TE), Área central total (TCA) e Área central das classes da paisagem BHRA, nos anos de 1991 e 2011.

\begin{tabular}{lrrrrrr}
\hline \multirow{2}{*}{$\begin{array}{c}\text { Cobertura vegetal } \\
\text { e usos da terra }\end{array}$} & \multicolumn{2}{c}{ TE (m) } & \multicolumn{2}{c}{ TCA (ha) } & \multicolumn{2}{c}{ CPLAND (\%) } \\
\cline { 2 - 7 } & $\mathbf{1 9 9 1}$ & $\mathbf{2 0 1 1}$ & $\mathbf{1 9 9 1}$ & $\mathbf{2 0 1 1}$ & $\mathbf{1 9 9 1}$ & $\mathbf{2 0 1 1}$ \\
\hline Savana (Cerrado) & $5.930,46$ & 805,04 & $115.000,74$ & 63.611 & 61 & 33 \\
Floresta aluvial & 1.328 .520 & 5.596 .920 & $3.489,12$ & 15.817 & 18,50 & 5 \\
Agropecuária & 1.323 .240 & 2.897 .400 & $18.207,54$ & 27.869 & 29 & 19 \\
Água & 78.810 & 66.840 & 207,270 & 144 & 0.1 & 0.08 \\
Influência urbana & - & 9.480 & - & 13,86 & - & 0.007 \\
\hline
\end{tabular}


Na classe de Savana (Cerrado) a inserção do uso agropecuário foi o fator preponderante para sua fragmentação, contribuindo para que os remanescentes desta classe apresentassem-se distantes um do outro 136 e 141 metros em 1991 e 2011, respectivamente (Figura 4). Indicando a antropização da bacia estudada, pois valores baixos de ENN ocorrem quando os fragmentos de vegetação estão mais agregados e, em paisagem antropizadas o valor tende a ser mais elevado, diminuindo à medida que os distúrbios são controlados (HARGIS et al., 1998).

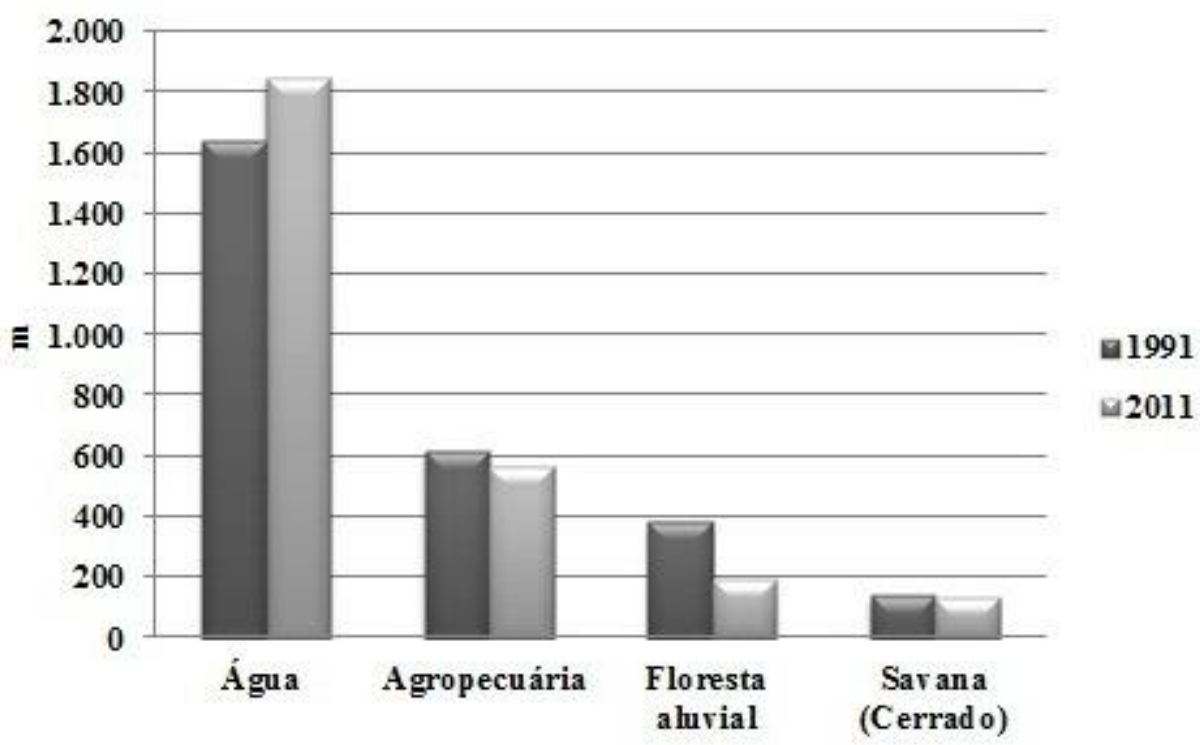

Figura 4. Distância euclidiana média do vizinho mais próximo das classes que compõem a paisagem da bacia nos anos de 1991 e 2011.

O padrão apresentado pela classe Cerrado da BHRA de acordo com Metzger (2001) pode ser fator determinante na realização de diferentes processos ecológicos como dispersão de sementes, polinização e fluxo gênico entre animais, implicando em prejuízos a conservação. Jarvinen (1982) acrescenta ainda que o grau de isolamento afeta diretamente a qualidade de um fragmento, por afetar a movimentação de organismos e a dispersão das espécies, implicando na taxa de crescimento de espécies de borda, que podem chegar a ocupar todo o remanescente.

A análise da classe Água, que apresentou o maior valor de distância, teve seu resultado influenciado pela resolução da imagem, pois quando a largura do canal do Rio Aguapeí foi inferior a $30 \mathrm{~m}$, correspondendo a menos de um pixel na imagem, não foi possível o seu mapeamento, sobressaindo a Floresta aluvial. 
No ano de 1991 a paisagem da bacia do Rio Aguapeí apresentou um total de 2.336 manchas de Agropecuária, assim distribuídas: 10,10\% em área inferior a 1 hectare; $87,07 \%$ entre 1 a 100 hectares; 2,69\% entre 101 a 1.000 hectares e $0,14 \%$ superior a 1.000 hectares. Em 2011 haviam 3.317 manchas de Agropecuária distribuídas da seguinte forma: 10,40\% eram menores que 1 hectare; 86,88\% encontram-se entre 1 e 100 hectares; $2,50 \%$ entre 101 e 1.000 hectares; e $0.22 \%$ eram maiores que 1.000 hectares (Tabela 3 ).

Estes dados indicam que utilização da terra na bacia na atualidade mantêm o mesmo padrão da década de 90, pois no período de analisado houve um crescimento de $30 \%$ no número de manchas, pertencente as classes de uso em detrimento da matriz, que a cada ano apresentou-se mais fragmentada. A fragmentação age fundamentalmente reduzindo e isolando as áreas propícias à sobrevivência das populações, sendo apontada como a principal causa da perda de biodiversidade (METZGER, 1999).

Tabela 3. Tamanho das manchas da área de estudo.

\begin{tabular}{lrrrr|rrrr}
\hline \multirow{2}{*}{ Mancha } & \multicolumn{4}{c|}{ 1991 } & \multicolumn{4}{c}{$\mathbf{c}$ Tamanho (ha) } \\
\cline { 2 - 9 } & \multicolumn{4}{c|}{ Tamanho (ha) } \\
\cline { 2 - 9 } & $<\mathbf{1 - 1 0 0}$ & $\mathbf{1 0 1 - 1 . 0 0 0}$ & $>\mathbf{1 . 0 0 0}$ & $<\mathbf{1}$ & $\mathbf{1 - 1 0 0}$ & $\mathbf{1 0 1 - 1 . 0 0 0}$ & $>\mathbf{1 . 0 0 0}$ \\
\hline Agropecuária & 236 & 2.034 & 63 & 3 & 345 & 2.882 & 83 & 7 \\
\hline
\end{tabular}

A análise da distribuição das manchas de Agropecuária mostrou que estas estão condicionadas as características geomorfológicas, visto que no ano de 1991 as manchas com tamanhos inferiores a 100 hectares estavam distribuídas aleatoriamente na bacia, independentemente das formas topográficas. Enquanto as manchas com mais de 100 hectares, ocorriam em áreas de relevo plano, suave ondulado e ondulado, ou seja, em áreas propícias ao uso. Este padrão foi mantido no ano de 2011, mas apresentando aumento na quantidade de manchas das mais distintas classes de tamanho. Segundo Batista et al. (2009) as combinações resultantes do relevo, dos tipos de substrato e solo ao longo da história evolutiva da região determinam as diversas composições, apontando grande variabilidade natural do meio físico que formam as paisagens.

O maior fragmento mapeado no ano de 1991, calculado pela métrica LPI, totalizou 69.644,9 ha pertencente a classe de Savana (Cerrado). Em 2011 o maior fragmento também foi da classe Savana (Cerrado), mas com tamanho menor, com 
33.499 hectares. Bierregarrd e Dale (1996) expuseram que fragmentos florestais com tamanho menor a 50 hectares estão totalmente sujeitos aos efeitos ocasionados pela presença de borda, enquanto fragmentos com mais de 100 hectares podem abranger uma diversidade considerável de espécies, com exceção dos grandes mamíferos.

A métrica COHESION para os anos de 1991 e 2011 apresentou como resultado para todas as classes de cobertura vegetal e uso da terra da bacia, em ambos os anos investigados, valores superiores a 87\%. Apesar da redução nas áreas de Savanas (Cerrado) os remanescentes ainda possuem uma conectividade física, o que é favorável para sua conservação da biodiversidade.

Segundo McGarigal e Marks (1995), percentuais relativas a essa métrica próximos a 100\% indicam que a classe tem maior agregação e, portanto, menos isolamento das manchas. Com base no exposto, as classes de uso e cobertura da terra da BHRA apresentaram conectividade, embora essa afirmação não seja conclusiva, pois existem outros fatores determinantes que devem ser considerados na avaliação da conectividade.

\section{CONCLUSÕES}

Na bacia Hidrográfica do Rio Aguapeí há o predomínio da vegetação natural de Savana (Cerrado) constituindo a matriz da paisagem. De acordo com os resultados das métricas de área verificou-se que a formação de manchas isoladas, com tamanho menor que 100 ha, estão relacionadas ao uso da terra (principalmente a atividade agropecuária) resultando futuramente, caso o padrão de uso da terra não seja modificado, na conversão da matriz de Savana (Cerrado) para uma matriz antropizada.

Constatou-se a ausência de vegetação ciliar (Áreas de Preservação Permanente) em alguns trechos das margens dos cursos d'água, o esta em desacordo com o previsto na legislação ambiental.

A forma de relevo tem contribuído na conservação da Savana (Cerrado), pois a ocorrência do maior fragmento desta classe está associada às feições morfológicas classificadas como escarpadas, montanhosas e forte ondulada, que ocorrem na Serra de Santa Bárbara. 
Em síntese a interpretação dos resultados obtidos a luz dos referenciais teóricos possibilitaram observar que a dinâmica de uso da terra na BHRA, que é direcionada pela economia regional baseada na Agropecuária, vem comprometendo a conservação dos elementos natural da paisagem, principalmente a vegetação, demandando mudanças nos mecanismos contidos nas políticas de desenvolvimento regional de Mato Grosso, visando melhorar a permeabilidade da paisagem.

\section{AGRADECIMENTOS}

Ao Conselho Nacional de Desenvolvimento Cientifico e Tecnológico - CNPq pela concessão da Bolsa de Iniciação Cientifica.

Trabalho derivado dos dados gerados no projeto "Modelagem de indicadores ambientais para a definição de áreas prioritárias e estratégicas à recuperação de áreas degradadas da região Sudoeste de Mato Grosso/MT" vinculado à Sub-rede de estudos sociais, ambientais e de tecnologias para o sistema produtivo na região sudoeste matogrossense - REDE ASA, financiada no âmbito do Edital MCT/CNPq/FNDCT/FAPs/MEC/CAPES/PRO-CENTRO-OESTE Nº 031/2010.

\section{REFERÊNCIAS}

BASKENT, E.Z. Assessment of structural dynamics in forest landscape management. Canadian Journal of Forestry Research, v. 27, n. 10, p. 1675-84, Oct., 1997.

BERTOLO, L. S. Medida de mudança espaço-temporal como fonte de identificação das linhas de evolução de paisagem costeira - Estudo de caso: Ilha de São Sebastião/SP 2009. 96 f. Dissertação (Mestrado em Engenharia Civil) - Faculdade de Engenharia Civil, Arquitetura, Universidade Estadual de Campinas, Campinas/SP, 2009.

BIERREGAARD, R. O.; DALE, V. H. Island in an ever-changing sea: the ecological and socioeconomic dynamics of Amazonian rainforest fragments. In: SCHELAS, J.; GRENBERG, R. (Ed.) Forest patches in tropical landscapes. Washington: Island Press, 1996. p. 187-204. 
BRASIL. Instituto Brasileiro de Geografia e Estatística. Manual técnico de pedologia. 2 ed. Rio de Janeiro: IBGE/Diretoria de Geociências, 2007. p. 189-191.

BRASIL. Ministério do Meio Ambiente. Relatório Probio-Pantanal, 2007. Disponível em: http://www.macroprograma1.cnptia.embrapa.br/projeto/probiopantanal/downloads1/documentos. Acesso em: 15 maio 2012.

CÂMARA, G,; SOUZA, R. C. M,; FREITAS, U. M.; GARRIDO, J. SPRING: Integrating remote sensingand GIS by object-oriented data modelling. Computers \& Graphics, 20: (3), p. 395-403. may-jun, 1996.

CUNHA, J. M. P. Dinâmica migratória e o processo de ocupação do Centro-Oeste brasileiro: o caso de Mato Grosso. R. Bras. Est. Pop., São Paulo, v. 23, n. 1, p. 87-107, jan./jun., 2006.

DIETZEL, C.; HEROLD, M.; HEMPHILL, J. J.; CLARKE, K.C. Spatio-temporal dynamics in California's Central Valley: empirical links to urban theory. International Journal of Geographical Information Science, v. 19, n. 2, p. 175 - 195, fev., 2005.

DUNNING, J. B.; DANIELSON, B. J.; PULLIAM, H. R. Ecological processes that affect populations in complex landscape. Oikos, v. 65, p. 169-175, 1992.

EGLER, C. A. G. Mudanças recentes no uso e na cobertura da terra no Brasil. In: Anais... Seminário mudanças ambientais globais: perspectivas brasileiras. Campinas: Nepo/Unicamp, $2000 . \quad$ Disponível em: http://www.laget.igeo.ufrj.br/egler/pdf/Uso_Completo.pdf. Acesso em: 23 abr. 2004.

ESRI. ArcGIS Desktop: release 9.2. Redlands, CA: Environmental Systems Research Institute, 2007.

FARR, T. G.; ROSEN, P.; CARO, E.; CRIPPEN, R.; DUREN, R.; HENSLEY, S.; KOBRICK, M.; PALLER, M.; RODRIGUEZ, E.; ROTH, L.; SEAL, D.; SHAFFER, S.; SHIMADA, J.; UMLAND， J.; WERNER， M.; OSKIN， M.; BURBANK， D.; ALSDORF, D. The Shuttle Radar Topography Mission. Rev. Geophys, 45, 2007. 
FLORENZANO, T. G. Imagens de satélite para estudos ambientais. São Paulo: Oficina de Textos, 2002.97p.

FORMAN, R. T. T.; GODROM, M. Landscape ecology. John Willey, New York, 1986. $619 \mathrm{p}$.

HARGIS, C. D.; BISSONETTE, J. A.; DAVID, J. L. The behavior of landscape metrics commonly used in the study of habitat fragmentation. Landscape Ecology, v. 13, p. 167186, 1998.

HEROLD, M.; GOLDSTEIN, N. C.; CLARKE, K. C. The spatiotemporal form of urban growth: measurement, analysis and modeling. Remote Sensing of Environment, v. 86, p. 286-302, 2003.

JARVINEN, O. Conservation of endangered plant populations: single large or several small reserves? Oikos, v.38, p. 301-307, 1982.

KOIVU, R. H. Agricultural landscape change: a case study in Yläne, southwest Finland. Landscape and Urban Planning, v. 43, p.103-108, 1999.

LEITÃO, A. B.; AHERN, J. Applying landscape ecological concepts and metrics in sustainable landscape planning. Landscape Urban Planning, v. 59, n. 2, p. 65-93, Abr., 2002.

MARSH, W. M. Landscape planning: environmental applications. 3 ed. John Willey, New York, 1997. 434p.

MATO GROSSO (Estado). Secretaria de Estado de Planejamento e Coordenação Geral. Plano de Longo Prazo de Mato Grosso: macro-objetivos, metas globais, eixos estratégicos e linhas estrutantes. In: PRADO, J. G. B.; BERTCHIELI, R.; OLIVEIRA, L. G. (Orgs). Plano de Longo Prazo de Mato Grosso. Cuiabá/MT: Central de Texto, vol. IV, 2012. 108p. Disponível em: http://www.seplan.mt.gov.br/mt20/mt20.htm. Acesso em: 22 jan. 2013. 
MCGARIGAL, K.; MARKS, B. J. FRAGSTATS: spatial pattern analysis program for quantifying landscape structure. Gen. Tech. Report PNW-GTR-351, USDA Forest Service, Pacific Northwest Research Station, Portland, OR, 1995. 122 p.

METZGER, J. P. Delineamento de experimentos numa perspectiva de Ecologia da Paisagem. In: CULLEN JR.; L.; RHUDRAM, R.; VALLADARES-PADUA, C. (Eds.) Métodos e técnicas na Biologia da Conservação e no manejo da vida silvestre. Curitiba: Universidade Federal do Paraná, 2003.

METZGER, J. P. Estrutura da Paisagem e fragmentação: análise bibliográfica. Anais... Academia Brasileira de Ciências, 71 (3-I): 445-463, 1999.

METZGER, J. P. O que é Ecologia de Paisagens? Biota Neotropica, v. 1, n.1, p 1- 9, 2001.

METZGER, J. P.; FONSECA, M. A.; OLIVEIRA FILHO, F. J. B.; MARTENSEN, A. C. O uso de modelos em ecologia de paisagens. Megadiversidade, v. 3, n. 1-2, p. 64-73, Dez., 2007.

METZGER, J. P.Como lidar com regras pouco óbvias para conservação da biodiversidade em paisagens fragmentadas. Natureza \& Conservação. v. 4, n 2, p. 11 23, 2006.

OLIVEIRA, I. J. Sustentabilidade de sistemas produtivos agrários em paisagens do cerrado: uma análise no município de Jataí (GO). Revista Terra Livre, ano 20, v. 2, n. 23, p. 139-159, jul.-dez., 2004.

RITTERS, K. H.; O’NEIL, R.V.; HUNSAKER, C. T.; WICKHAM, J. D.; YANKEE, D. H. TIMMINS, S. P. A factor analysis of landscape pattern and structure metrics. Landscape Ecology, v.10, n.1, p. 23-39, 1995.

SANTOS, R. F. Planejamento ambiental: teoria e prática. São Paulo: Oficina de Textos. 2004. p. 143.

SANTOS, R. F. (Org.). Vulnerabilidade Ambiental: Desastres naturais ou fenômenos induzidos? Brasília - DF: Ministério do Meio Ambiente, 2007. 191p. 
SEVEGNANI, L.; SILVA, T. C.; GASPER, A. L.; MEYER, L.; VERDI, M. Flora arbórea e o impacto humano nos fragmentos florestais na bacia do rio Pelotas, Santa Catarina, Brasil. REA - Revista de estudos ambientais, v.14, n.1, p. 60-73, 2012.

SILVA, J. S. V.; ABDON, M. M. NEVES, S. M. A. S.; MORAES, J. A. Evolution of deforestation in the brasilian Pantanal and surroundings in the timeframe 1976-2008. Geografia, v. 36, p. 35-56, jun., 2011.

TURNER, M. G. Landscape ecology: the effect of pattern on process. Annual Review of Ecology and Systematics, v. 20, p. 171-197, 1989.

TURNER, M. G.; WEAR, D. N.; FLAMM, R. O. Land ownership and land-cover change in the southern Appalachian highlands and the Olympic peninsula. Ecological Applications, v 4, p. 1150-1172, 1996.

VALENTE, R. A. Análise da estrutura da paisagem na bacia do Rio Corumbataí/SP. 2001. 144 f. Dissertações (Mestrado em Recursos Florestais) - Departamento de Escola Superior de Agricultura Luiz de Queiroz, Universidade de São Paulo, Piracicaba/SP, 2001 .

VIEIRA, E. H. A. Conservação ambiental em cenários de uso: medidas de mudanças, heterogeneidade e valoração da paisagem. 2010. 212 f. Tese (Doutorado em Engenharia Civil) - Faculdade de Engenharia Civil, Arquitetura, Universidade Estadual de Campinas, Campinas/SP, 2010.

WIENS, J. A.; MOSS, M. Studies in landscape ecology: issue and perspectives in landscape ecology. Cambridge University Press, Cambridge, UK, p 365-373, 2005.

Artigo recebido para publicação em março de 2014.

Artigo aceito para publicação em outubro de 2014. 